\title{
WestVirginiaUniversity。
}

Department of Economics

Working Paper Series

\section{Theory of Mind Predicts Cooperative Behavior}

Gregory DeAngelo

Bryan C. McCannon

Working Paper No. 16-16

This paper can be found at the College of Business and Economics Working Paper Series homepage: 


\title{
Theory of Mind Predicts Cooperative Behavior
}

\author{
Gregory DeAngelo \\ West Virginia University \\ Bryan C. McCannon \\ West Virginia University
}

23 November 2015

\begin{abstract}
Explanations for cooperation in Prisoner's Dilemma games (PD) have generated significant interest. While institutional explanations, such as the role of repeated interactions and communication, have offered considerable explanatory ability, a psychological measure of Theory of the Mind (ToM) Reading the Mind in the Eyes - of an individual's ability to process social and emotional cognition offers new insights. Using this measure, we examine how ToM explains (un)cooperative behavior in a standard PD game. We find that subjects who have higher ToM are less cooperative in PD games and extract higher payoffs.
\end{abstract}

Keywords: Cooperation, Experiment, Prisoner's Dilemma, Reading Mind in the Eyes, Theory of the Mind

\section{Introduction}

The sources of cooperative behavior have been the subject of numerous research interest in biology, psychology, sociology, and economics. In standard cooperative environments, such as the famous Prisoner's Dilemma, mutually-beneficial, social welfare-maximizing outcomes contrast with selfish, individually-rational behavior that leads to socially destructive outcomes. Therefore, the facilitation of cooperation is an important issue to understand.

Initial research into the drivers of cooperation focused on institutional features that may facilitate it, such as reputation through repeated play (Axelrod, 1981; Axelrod and Hamilton, 1981), incomplete information (Kreps, Milgrom, Roberts, and Wilson, 1982), communication (Miettinen and Suetens, 2008), and sanctioning (Xiao and Kunreuther, 2013). New efforts have been put forth to explain individual differences in willingness to cooperate. For example, Boone, De Brabander and van Witteloostuijn (1999), Hirsch and Peterson (2009) and Kagel and McGee (2014) use a common 
assessment of personality traits, as measured in social psychology and used in management education and training, as a covariate of cooperation.

We investigate the psychological concept of Theory of the Mind (ToM) as an explanation of cooperation. Simple ToM assessments have been used in economic experiments with children to appreciate child development (Takagishi et al., 2010) and the effects of autism (Sally and Hill, 2006). We explore the "Reading the Mind in the Eyes" (henceforth, Eyes score) assessment (Baron-Cohen, 1991; Baron-Cohen et al., 2001) where subjects view photos of professional actors emoting by examining a photo that is cropped to display only their eyes, eye brows and a portion of their nose (see Appendix Figure A2). Subjects are then asked to evaluate the emotion being experienced by the actor. Their responses are added together to determine their Eyes score, which is on a scale of $0-36$. Subjects who record a greater number of correctly-assessed scenarios are thought to be those who are more capable of attributing mental states (beliefs, desires, intents, etc.) to oneself and others, while understanding that other people might have mental states that differ from their own (Baron-Cohen, 1991). Such a skill in a person can be expected to enable one to understand that mental states can be the cause of the behavior of others (Premack and Woodruff, 1978).

Given that cooperative behavior requires the subject to engage in strategic behavior, forming expectations about the potential choices and beliefs of the opponent, one would expect that differences in the Eyes scores (as a measure of ToM) correlates with a subject's ability to strategically cooperate or defect. In cooperative games, an appreciation for the incentives faced by one's opponent can be expected to lead an individual to respond appropriately. ${ }^{1}$

A standard laboratory experiment common in economics is conducted. Subjects played the game known as the Prisoner's Dilemma. In it, two subjects are randomly and anonymously paired in a one-shot game. Each simultaneously selects one of two actions. One is a cooperative strategy where if both select this strategy, then both receive a high payoff. If both select the other, non-cooperative strategy, both receive a low payment. The dilemma is that if the opponent selects the cooperative strategy an even greater payoff can be earned by deviating to the non-cooperative action. Thus, cooperation is dominated by non-cooperation in wealth-maximizing individuals.

Subjects also engage in the Eyes assessment. The relationship between their score on the assessment and their behavior in the laboratory is analyzed. In the laboratory game approximately $60 \%$

\footnotetext{
${ }^{1}$ Using an alternative Theory of Mind assessment, Sally and Hill (2006) consider children with and without autism. The sub-group who performed well on the ToM assessment were more likely to exploit cooperation claiming that, "theory-of-mind is necessary to respond in a strategic fashion in the Prisoner's Dilemma" (p.84).
} 
of the subjects select the cooperative strategy. Thus, a subject randomly paired with another in the lab, accurately anticipating behavior by recognizing the beliefs and incentives of others, would find the noncooperative strategy preferable. We present evidence that this is the case. Subjects who score higher on the ToM assessment cooperate less. Consequently, they earn a greater payoff in the game. This result is robust to the inclusion of other risk and ambiguity preferences and measures of competence levels.

Section II describes the methods employed. Section III summarizes the results from the laboratory, while Section IV presents our empirical results. Section V concludes.

\section{Methods}

We conducted the experiments at Rensselaer Polytechnic Institute (RPI), Union College (Union), and the University of Massachusetts (UMass) during a six-month time frame. In total there were 141 subjects across the three institutions. ${ }^{2}$ Subjects were recruited using the Online Recruitment System for Economic Experiments (ORSEE) (Greiner, 2004) and were informed that they would be financially compensated for their participation in a two-part survey.

Upon signing up to participate in the experiment, subjects were given immediate access to complete the first part of the experiment. This entailed completing a survey. The survey collected background information, questions involving decision making under uncertainty assessments, and the Eyes assessment. Specifically, the decision making under uncertainty assessments included an assessment of the Allais and Ellsberg paradoxes and a measure of risk aversion (see Tables A1 and A2 in the appendix). The Allais Paradox assesses whether subjects exhibit a bias for certain outcomes (Allais, 1953), whereas the Ellsberg Paradox assesses whether subjects exhibit an aversion for ambiguous decision problems (Ellsberg, 1961). ${ }^{3}$ These tests were taken using an online survey format, and subjects were given a 45 minute time limit.

The "Reading the Mind in the Eyes" test was developed by Baron-Cohen (1991) and BaronCohen et al. (2001) to be an advanced test of the Theory of the Mind. The assessment provides thirty-six photographs of actors and actresses showing the facial region around the eyes. The subject is asked to choose which of four words best describes what the person in the photograph is thinking or feeling. These words refer to both basic mental states (e.g. happy) and complex mental states (e.g. arrogant).

\footnotetext{
${ }^{2}$ The distribution of subjects across the three locations is 72,38 , and 32 at RPI, Union, and UMass, respectively. ${ }^{3}$ Ambiguity aversion differs from risk aversion in that subjects are not informed of the objective probabilities but rather must first form beliefs about the possibility distribution functions over the state of potential outcomes.
} 
The assessment aims to evaluate social and emotional cognition. It has been used to evaluate the effects of schizophrenia (De Achaval et al., 2010), autism (Baron-Cohen, 2009), eating disorders (Adenzato et al., 2012), Asperger Syndrome (Senju et al., 2009), bipolar disorder (Derntl et al., 2009), and social anxiety (Machado-de-Sousa et al., 2010) to name a few. Its stability over time has been established (Fernandez-Abascal et al., 2013) and it has been shown to relate to biological factors. For example, ToM is promoted by the administration of Oxytocin (Domes et al., 2007) and is inversely correlated with fetal testosterone exposure (Chapman et al., 2006), is independent of episodic memory (Rosenbaum et al., 2007) and short-term improvement can be facilitated through literary fiction (Comer Kidd and Castano, 2013).

Approximately 1-2 weeks after completing the survey, the subjects were asked to report to a computer lab to participate in the economics games. The subjects were randomly assigned to a computer cubicle and informed they would be randomly and anonymously paired with another subject in a one-shot game.

A one-shot Prisoner's Dilemma Game was implemented in the laboratory. The Prisoner's Dilemma presents subjects with the opportunity to benefit from mutual cooperation, but also with the potential to obtain an even larger benefit by exploiting cooperative efforts. ${ }^{4}$ This is often captured in a choice problem played amongst two subjects that have a choice between action "Up" or action "Down", while their opponent selected either "Left" or "Right". 5

Along with the instructions, a payoff matrix was shown on the computer screen (Figure A1 in the appendix provides the matrix seen by the subjects). If the outcome $<U p$, Left $>$ is selected, then both players would receive \$4. Thus, Up and Left are the cooperative choices. If <Down, Right $>$ arises, then they both receive $\$ 1$. Furthermore, as is standard in the Prisoner's Dilemma, if $<U p$, Right $>$ or $<$ Down, Left> occurs, then the player selecting the cooperative strategy receives $\$ 0$, while the other earns $\$ 5$. Thus, the dominant strategy for a subject who is interested in maximizing monetary wealth in the oneshot environment is to select Down. A subject attempting to cooperate on the social welfare maximizing outcome selects Up. The game was played once. We create a variable Prison that takes on a value of one if the individual selected the cooperative action (Up), and zero otherwise. Additionally, a variable Prison Outcome is created that is equal to the amount earned by the subject in the game, which can take on values of $0,1,4$, or 5 .

\footnotetext{
${ }^{4}$ See Axelrod and Hamilton (1981) for one of the earliest discussions of behavior in the Prisoner's Dilemma. ${ }^{5}$ Figure $A 1$ in the Appendix A1 provides a visualization of the game that all subjects played. For simplicity, all decision makers made the Up or Down decision so that to determine the outcome Left and Up are treated as equivalent choices, as were Down and Right.
} 
After the subjects completed the game, they were then asked how much of $\$ 5$ they would like to keep. This was done to identify those with nonstandard preferences. The payoff from the game was added to the $\$ 15$ that the subject was paid for completing the survey, then a \$5 show-up payment was added to determine each subject's final pay. The average payment earned in the Prisoner's Dilemma game was $\$ 2.74$.

\section{Summary of Results from the Laboratory}

Table 1 presents the descriptive statistics of the variables used in the analysis.

Table 1: Descriptive Statistics - Full Sample

\begin{tabular}{|c|c|c|c|}
\hline Label & Description & Mean & St. Dev. \\
\hline Prison & $\begin{array}{l}=1 \text { if the subject selected the cooperative } \\
\text { strategy ("Up") }\end{array}$ & 0.596 & 0.493 \\
\hline Eyes & $\begin{array}{l}\text { \# of correct choices in the Reading Mind in } \\
\text { the Eyes assessment }(\min =0 ; \max =34)\end{array}$ & 27.12 & 3.67 \\
\hline \multicolumn{4}{|c|}{ Controls (see Tables A2 \& A3 for details) } \\
\hline Vocab & score on vocabulary assessment $(\max =10)$ & 7.65 & 1.43 \\
\hline IQ & score on IQ assessment $(\max =5)$ & 2.56 & 1.59 \\
\hline Ells Consistent & $=1$ if Ellsberg 1 = Ellsberg 2 & 0.582 & 0.497 \\
\hline Allais Consistent & $=1$ if Allais $1=$ Allais 2 & 0.567 & 0.495 \\
\hline Safe & \# of safe choices made (see Table A1) & 5.40 & 1.61 \\
\hline
\end{tabular}

The cooperative strategy is selected by approximately $60 \%$ of the subjects. For each assessment, while a majority exhibit consistent decision making under uncertainty preferences, only $27 \%$ exhibited consistency in both. The mean (and median) subject is risk averse, since a risk neutral, expected utility maximizer would select the safer option four times. In the population, though, $77 \%$ of the subjects are registered as being risk averse.

Does a subject's ToM correlate with their behavior? Table 1 presents the proportion of subjects who selected the cooperative strategy across various values of Eyes. The sample is broken down into 
those observations where the ToM measurement is greater than one standard deviation above the mean (first column), those within a standard deviation of the mean (second column), and those where the measurement is more than one standard deviation below the mean (third column).

Figure 1: Eyes in the Mind and Cooperation

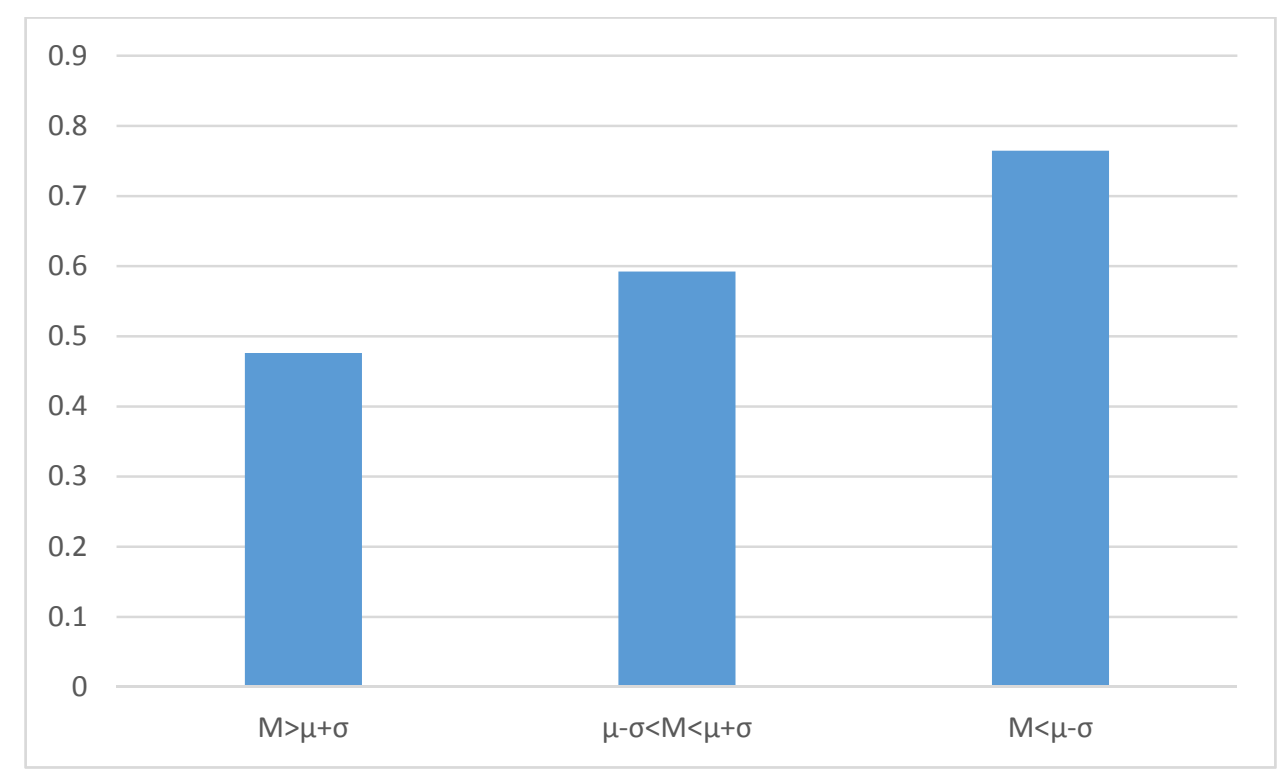

Subjects with the highest values cooperate the least. Those who score more than one standard deviation above the mean ( $>30$ ) cooperate less than $48 \%$ of the time. Those who score more than one standard deviation below the mean $(<24)$ cooperate over $76 \%$ of the time (a $60 \%$ increase in the rate of cooperation). ${ }^{6}$ A further analysis is needed to isolate and identify the statistical significance of this effect.

\section{Results}

A binary probit model is estimated with Prison as the dependent variable, which is equal to one if and only if the subject chose to cooperate. Background controls for gender, year in school, undergraduate

\footnotetext{
${ }^{6}$ Consistent with previous research, there is a relationship between gender and ToM (Kirkland et al., 2013). The correlation between Male and Eyes is -0.11 ( $p$-value $<0.2$ )
} 
major, and session fixed effects are included. Risk and uncertainty preferences, along with competence, are included as control variables to take into account important differences between individuals. Table 2 presents the results.

Table 2: Eyes in the Mind and Prisoner's Dilemma

(Probit, dependent variable $=$ Prison)

\begin{tabular}{|c|c|c|c|}
\hline & Coefficient & $\begin{array}{l}\text { Marginal } \\
\text { Effect }\end{array}$ & $\begin{array}{l}\text { Standard } \\
\text { Error }\end{array}$ \\
\hline Eyes & -0.074 & {$[-0.028]$} & $(0.029) * * *$ \\
\hline Male & -0.497 & {$[-0.186]$} & $(0.208)^{* *}$ \\
\hline Allais Consistent & 0.230 & [0.089] & $(0.161)$ \\
\hline Ellsberg Consistent & -0.194 & {$[-0.074]$} & $(0.239)$ \\
\hline In Safe & 0.616 & {$[0.236]$} & $(0.162) * * *$ \\
\hline IQ & 0.149 & {$[0.057]$} & $(0.100)$ \\
\hline Vocab & 0.273 & [0.105] & $(0.085)^{* * *}$ \\
\hline McFadden $\mathrm{R}^{2}$ & \multicolumn{3}{|l|}{0.133} \\
\hline $\mathrm{AIC}$ & \multicolumn{3}{|l|}{201.2} \\
\hline$\%$ correct & \multicolumn{3}{|l|}{$65.5 \%$} \\
\hline \multicolumn{4}{|c|}{ 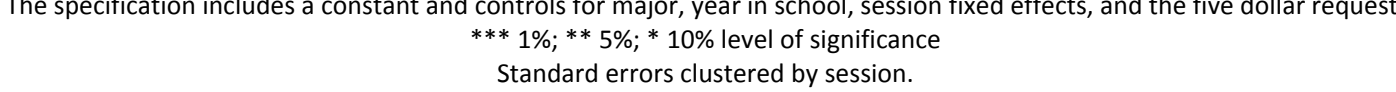 } \\
\hline
\end{tabular}

The results indicate a strong, negative relationship between a subject's Eyes score and cooperation. Using the marginal effect at the mean, a one standard deviation increase in a subject's Eyes score decreases the probability of cooperation by 10.6 percentage points (a $17.2 \%$ decrease from the mean).

Along with ToM, gender, risk preferences, and competence also independently and statistically significantly correlate with the decision to cooperate. Women, more risk averse, and less competent subjects have higher levels of cooperation. The Eyes score is pairwise uncorrelated (at the $5 \%$ level) with each of the other explanatory variables, except Vocab. The coefficient on Eyes retains its sign and statistical significance if Vocab is omitted. 
The statistical significance of Eyes persists if (i) a logit specification is estimated, (ii) unadjusted or QML standard errors are calculated, (iii) the Eyes score is log-transformed, or (iv) the control variables are dropped from the specification. Thus, the results are robust to alternative specifications.

In our laboratory sessions, cooperation is selected by $59.7 \%$ of the subjects. Therefore, if a subject is randomly paired in the laboratory and anticipated this frequency of play, then the expected monetary payment from cooperating is $4 \times 0.597=\$ 2.39$, while the expected payment from not cooperating is $(5 \times 0.597)+(1 \times 0.403)=\$ 3.39$. Our results suggest that subjects with higher ToM recognize this distribution of behavior and select the non-cooperative choice to increase their payoff. In our study, the subsample of those whose Eyes score was more than one standard deviation above the mean earned, on average, $\$ 3.38$, while the rest of the sample earned $\$ 2.62$.

This behavior cannot be explained by the argument that the ToM measurement is simply a measurement of intelligence. While Eyes is correlated with Vocab $(r=0.20 ; p$-value $<0.02)$ and related with $I Q(r=.12 ; p$-value $>0.16)$, there is not a strong interaction effect between either of these variables and the Prison variable. If interaction terms between Eyes and the two competence measurements are included, their coefficients are statistically insignificant. ${ }^{7}$

\section{Conclusion}

Theory of Mind postulates that individuals differ in their ability to assess their environment as they interact with others. We hypothesize that this should correlate with strategic decision making. We consider the important issue of cooperation in Prisoner's Dilemma games and find that individuals who are recorded as having higher ToM cooperate less. Presumably, they recognize the incentives faced by their potential opponents and that they will respond accordingly; rather, more accurately assessing the distribution of cooperative subjects and utilizing this information to generate higher payoffs during the experiment.

Our results indicate that this logic is correct. Those with a higher Reading the Mind in the Eyes score are less likely to cooperate and, consequently, given the behavior of the other subjects in the laboratory, earn a greater payoff.

It is important to emphasize that the experimental design did not allow for direct interaction between the subjects. Decisions were made anonymously and confidentially. Furthermore, the

\footnotetext{
${ }^{7}$ In fact, each pairwise interaction term between Eyes and every other control variable is statistically insignificant.
} 
experiment was conducted as a one-shot game, so there could be no adaptation, learning, or reputational effects. Thus, the ToM assessment is capturing an independent mental ability of subjects that correlates with cooperative behavior.

\section{References}

Adenzato Mauro, Patrizia Todisco, Rita B. Ardito (2012), Social Cognition in Anorexia Nervosa: Evidence of Preserved Theory of Mind and Impaired Emotional Functioning, PLOS One 7(8): e44414.

Allais, M. (1953), Le Comportement de l'Homme Rationnel Devant Le Risque: Critique des Psotulats et Axiomes de l’Ecole Americaine, Econometrica 21(4): 503-546.

Axelrod, Robert (1981), The Emergence of Cooperation amongst Egoists, American Political Science Review 75(2): 306-318.

Axelrod, Robert and William D. Hamilton (1981), The Evolution of Cooperation, Science 211(4489): 13901396.

Baron-Cohen, Simon (1991), Precursors to a Theory of Mind: Understanding Attention in Others, in Whiten, Andrew (ed.), Natural Theories of the Mind: Evolution, Development, and Simulation of Everyday Mind-Reading, Cambridge, MA: Basil Blackwell, pp. 233-250.

Baron-Cohen S. (2009), Autism: the Empathizing-Systemizing (E-S) Theory, Annals of the New York Academy of Sciences 1156(1): 68-80.

Baron-Cohen, Simon, Sally Wheelwright, Jacqueline Hill, Yogini Raste, and lan Plumb (2001), The 'Reading the Mind in the Eyes' Test Revised Version: A Study with Normal Adults, and Adults with Asperger Syndrome of High-Functioning Autism, Journal of Child Psychology and Psychiatry 42(2): 241251.

Boone, Christophe, Burt De Brabander and Arjen van Witteloostuijn (1999), The Impact of Personality on Behavior in Five Prisoner's Dilemma Games, Journal of Economic Psychology 20(3):343-377. 
Chapman, Emma, Simon Baron-Cohen, Bonnie Auyeung, Rebecca Knickmeyer, Kevin Taylor, and Gerald Hackett (2006), Fetal Testosterone and Empathy: Evidence from the Empathy Quotient (EQ) and the "Reading the Mind in the Eyes" Test, Social Neuroscience 1(2): 135-148.

Comer Kidd, David, and Emmanuele Castano (2013), Reading Literary Fiction Improves Theory of Mind, Science 342(6156): 377-380.

De Achával Delfina, Elsa Y. Costanzo, Mirta Villarreal, Ignacio O. Jáuregui, Araceli Chiodi, Mariana N. Castro, Rodolfo D. Fahrer, Ramon C. Leiguarda, Elvina M. Chu, Salvador M. Guinjoan (2010), Emotion Processing and Theory of Mind in Schizophrenia Patients and Their Unaffected First-Degree Relatives, Neuropsychologia 48: 1209-1215.

Derntl Birgit, Eva-Maria Seidel, Ilse Kryspin-Exner, Alexander Hasmann, Matthias Dobmeier (2009), Facial Emotion Recognition in Patients with Bipolar I and Bipolar II Disorder, British Journal of Clinical Psychology 48(4): 363-375.

Domes, Gregor, Markus Heinrichs, Andre Michel, Christoph Berger, and Sabine C. Herpertz (2007), Oxytocin Improves "Mind-Reading" in Humans, Biological Psychiatry 61(6): 731-733.

Fernandez-Abascal, Enrique G., Rosario Cabello, Pablo Fernandez-Berrocal, and Simon Baron-Cohen (2013), Test-Retest Reliability of the 'Reading the Mind in the Eyes' Test: A One-Year Follow-Up Study, Molecular Autism 4(1): 33-38.

Greiner, Ben (2004), An Online Recruitment System for Economic Experiments, in Kurt Kremer and Volker Macho (Eds.), Forschung und Wissenschaftliches Rechnen 2003, Gesellschaft für Wissenschaftliche Datenverarbeitung Göttingen, Göttingen, 79-93

Hirsch, Jacob B., and Jordan B. Peterson (2009), Extraversion, Neuroticism, and the Prisoner's Dilemma, Personality and Individual Differences 46(2): 254-256. 
Hoffman, Elizabeth, Kevin A. McCabe, and Vernon L. Smith (1998), Behavioral Foundations of Reciprocity: Experimental Economics and Evolutionary Psychology, Economic Inquiry 36(3), 335-352.

Holt, Charles A., and Susan K. Laury (2002), Risk Aversion and Incentive Effects, American Economic Review 95(2): 1644-1655.

Ellsberg, Daniel (1961), Risk, Ambiguity, and the Savage Axioms, Quarterly Journal of Economics 75(4): 643-669.

Kagel, John, and Peter McGee (2014), Personality and Cooperation in Finitely Repeated Prisoner's Dilemma Games, Economics Letters 124(2): 274-277.

Kirkland, Rena A., Eric Peterson, Crystal A. Baker, Stephanie Miller, and Steven Pulos (2013), MetaAnalysis Reveals Adult Female Superiority in "Reading the Mind in the Eyes Test", North American Journal of Psychology 15(1): 121-146.

Kreps, David, Paul Milgrom, John Roberts, and Robert Wilson (1982), Rational Cooperation in the Finitely Repeated Prisoner's Dilemma, Journal of Economic Theory 27(2): 245-252.

Machado-de-Sousa Joao Paulo, Katia C. Arrais, Nelson T. Alves, Marcos H. N. Chagas, Carolina de Meneses-Gaya, Jose Alexandre de S. Crippa, Jaime Eduardo C. Hallak (2010), Facial Affect Processing in Social Anxiety: Tasks and Stimuli, Journal of Neuroscience Methods 2010, 193 (1): 1-6.

Miettinen, Topi, and Sigrid Suetens (2008), Communication and Guilt in a Prisoner's Dilemma, Journal of Conflict Resolution 52(6): 945-960.

Pelligra, Vittorio, Andrea Isoni, Roberta Fadda, Giuseppe Doneddu (2015), Theory of the Mind, Perceived Intentions and Reciprocal Behaviour: Evidence from Individuals with Autism Spectrum, Journal of Economic Psychology 49, 95-107.

Premack, David, and Guy Woodruff (1978), Does the Chimpanzee Have a Theory of Mind?, Behavioral and Brain Sciences 1(4): 515-526. 
Rosenbaum, R. Shayna, Donald T. Stuss, Brian Levine, and Endel Tuving (2007), Theory of Mind is Independent of Episodic Memory, Science 318(5854): 1257.

Sally, David, and Elisabeth Hill (2006), The Development of Interpersonal Strategy: Autism, Theory-ofMind, Cooperation, and Fairness, Journal of Economic Psychology 27(1): 73-97.

Scharleman, Jorn P.W., Catherine C. Eckel, Alex Kacelnik, and Rick K. Wilson (2001), The Value of a Smile: Game Theory with a Human Face, Journal of Economic Psychology 22(5): 617-640.

Senju, Atsushi, Victoria Southgate, Sarah White, and Uta Firth (2009), Mindblind Eyes: An Absence of Spontaneous Theory of Mind in Asperger Syndrome, Science 325(5942): 883-885.

Takagishi, Haruto, Shinya Kameshima, Joanne Schug, Michiko Koizumi, and Toshio Yamagishi (2010), Theory of Mind Enhances Preferences for Fairness, Journal of Experimental and Child Psychology 105(1): 130-137.

Xiao, Erte, and Howard Kunreuther (2013), Punishment and Cooperation in Stochastic Social Dilemmas, Working Paper. 


\section{Appendix}

Table A1 provides the risk assessment used in the experimental sessions.

Table A1: Risk Assessment

\begin{tabular}{|c|c|c|c|}
\hline \multirow{3}{*}{1.} & \multicolumn{2}{|c|}{ Option A } & Option B \\
\hline & $\$ 6$ & if 1 & $\$ 11.55$ if 1 \\
\hline & $\$ 4.80$ & if $2,3,4,5,6,7,8,9,10$ & $\$ 0.30$ if $2,3,4,5,6,7,8,9,10$ \\
\hline \multirow[t]{2}{*}{2.} & $\$ 6$ & if 1,2 & $\$ 11.55$ if 1,2 \\
\hline & $\$ 4.80$ & if $3,4,5,6,7,8,9,10$ & $\$ 0.30$ if $3,4,5,6,7,8,9,10$ \\
\hline \multirow[t]{2}{*}{3.} & $\$ 6$ & if $1,2,3$ & $\$ 11.55$ if $1,2,3$ \\
\hline & $\$ 4.80$ & if $4,5,6,7,8,9,10$ & $\$ 0.30$ if $4,5,6,7,8,9,10$ \\
\hline \multirow[t]{2}{*}{4.} & $\$ 6$ & if $1,2,3,4$ & $\$ 11.55$ if $1,2,3,4$ \\
\hline & $\$ 4.80$ & if $5,6,7,8,9,10$ & $\$ 0.30$ if $5,6,7,8,9,10$ \\
\hline \multirow[t]{2}{*}{5.} & $\$ 6$ & if $1,2,3,4,5$ & $\$ 11.55$ if $1,2,3,4,5$ \\
\hline & $\$ 4.80$ & if $6,7,8,9,10$ & $\$ 0.30$ if $6,7,8,9,10$ \\
\hline \multirow[t]{2}{*}{6.} & $\$ 6$ & if $1,2,3,4,5,6$ & $\$ 11.55$ if $1,2,3,4,5,6$ \\
\hline & $\$ 4.80$ & if $7,8,9,10$ & $\$ 0.30$ if $7,8,9,10$ \\
\hline \multirow[t]{2}{*}{7.} & $\$ 6$ & if $1,2,3,4,5,6,7$ & $\$ 11.55$ if $1,2,3,4,5,6,7$ \\
\hline & $\$ 4.80$ & if $8,9,10$ & $\$ 0.30$ if $8,9,10$ \\
\hline \multirow[t]{2}{*}{8.} & $\$ 6$ & if $1,2,3,4,5,6,7,8$ & $\$ 11.55$ if $1,2,3,4,5,6,7,8$ \\
\hline & $\$ 4.80$ & if 9,10 & $\$ 0.30$ if 9,10 \\
\hline \multirow[t]{2}{*}{9.} & & if $1,2,3,4,5,6,7,8,9$ & $\$ 11.55$ if $1,2,3,4,5,6,7,8,9$ \\
\hline & $\$ 4.80$ & if 10 & $\$ 0.30$ if 10 \\
\hline
\end{tabular}

The variable Safe equals the number of selections, out of the nine, in which option A was selected 
Suppose that an urn contains 300 balls and three possible colors: red, green, and blue. You know the urn contains exactly 100 red balls, but are given no information on how many green or blue balls are among the remaining 200 balls.

E1: $\quad$ You win if you guess which color will be drawn. Do you prefer to bet on

Red

Green

E2: $\quad$ Now suppose that you win if you guess that either of the two colors will be drawn. Do you prefer to bet that green or blue will be drawn or that red or blue will be drawn?

Green or Blue

Red or Blue

Choose either:

A1: $\quad$ A Chance of winning $\$ 4000$ with probability 0.2

A2: A chance of winning $\$ 3000$ with probability 0.25

Choose either:

B1: $\quad$ A chance of winning $\$ 4000$ with probability 0.8

B2: $\quad$ A chance of winning $\$ 3000$ with certainty.

In this assessment, the variable Ellsberg $1=1$ if Red is selected for E1 and Ellsberg $2=1$ if Green or Blue is selected for E2. A subject has Ellsberg Consistent = 1 if and only if Ellsberg $1=$ Ellsberg 2. In the second assessment, Allais $1=1$ if $\mathrm{A} 1$ is selected, Allais $2=1$ if $\mathrm{B} 1$ is selected. A subject has Allais Consistent = 1 if and only if Allais 1 = Allais 2 .

Figure A1 provides a screenshot of the Prisoner's Dilemma 
Figure A1: Prisoner's Dilemma

\begin{tabular}{l|cc}
\multicolumn{1}{l|}{ Their choice } & Right \\
Your choice & Left & $\$ 0, \$ 5$ \\
\hline Up & $\$ 4, \$ 4$ & $\$ 1, \$ 1$ \\
\hline
\end{tabular}

Figure A2 presents an example from the Mind of the Eye assessment.

Figure A2: Example

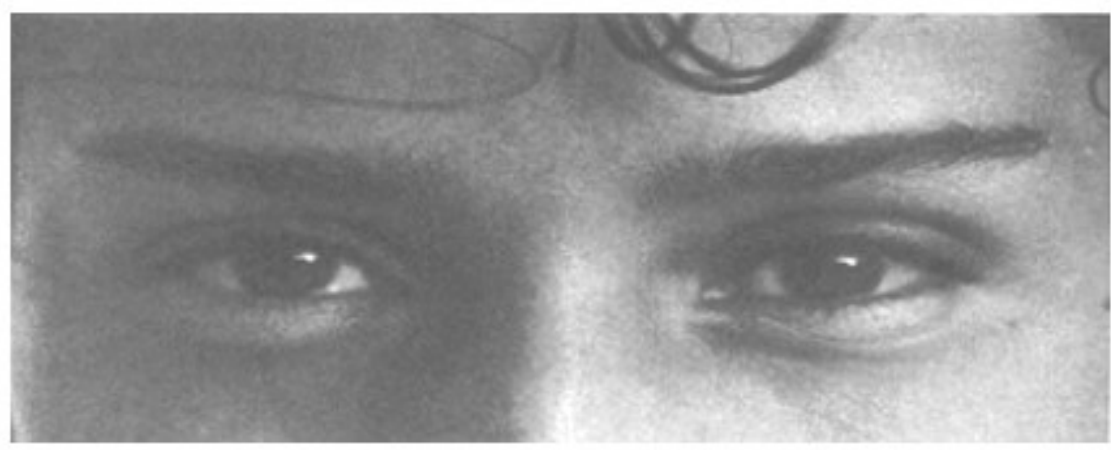

* Which emotion are the eyes showing?
C Playful
C Comforting
C Irritated
C Bored 